\title{
Nicotinic Mechanisms Modulate Ethanol Withdrawal and Modify Time Course and Symptoms Severity of Simultaneous Withdrawal from Alcohol and Nicotine
}

\author{
Erika Perez ${ }^{1,2}$, Natalia Quijano-Cardé ${ }^{3}$ and Mariella De Biasi',1,2,4 \\ 'Department of Neuroscience, Perelman School of Medicine at the University of Pennsylvania, Philadelphia, PA, USA; ${ }^{2}$ Department of \\ Neuroscience, Baylor College of Medicine, Houston, TX, USA; ${ }^{3}$ University of Puerto Rico at Mayagüez, Mayagüez, Puerto Rico; ${ }^{4}$ Department \\ of Psychiatry, Perelman School of Medicine at the University of Pennsylvania, Philadelphia, PA, USA
}

\begin{abstract}
Alcohol and nicotine are among the top causes of preventable death in the United States. Unfortunately, people who are dependent on alcohol are more likely to smoke than individuals in the general population. Similarly, smokers are more likely to abuse alcohol. Alcohol and nicotine codependence affects health in many ways and leads to poorer treatment outcomes in subjects who want to quit. This study examined the interaction of alcohol and nicotine during withdrawal and compared abstinence symptoms during withdrawal from one of the two drugs only vs both. Our results indicate that simultaneous withdrawal from alcohol and nicotine produces physical symptoms that are more severe and last longer than those experienced during withdrawal from one of the two drugs alone. In animals experiencing withdrawal after chronic ethanol treatment, acute nicotine exposure was sufficient to prevent abstinence symptoms. Similarly, symptoms were prevented when alcohol was injected acutely in mice undergoing nicotine withdrawal. These experiments provide evidence for the involvement of the nicotinic cholinergic system in alcohol withdrawal. Furthermore, the outcomes of intracranial microinfusions of mecamylamine, a nonselective nicotinic receptor antagonist, highlight a major role for the nicotinic receptors expressed in medial habenula and interpeduncular nucleus during withdrawal. Overall, the data support the notion that modulating the nicotinic cholinergic system might help to maintain long-term abstinence from alcohol.

Neuropsychopharmacology (20I5) 40, 2327-2336; doi: I0.I038/npp.20I5.80; published online 8 April 2015
\end{abstract}

\section{INTRODUCTION}

Alcohol use disorder is a major cause of economical and societal problems. Up to $4 \%$ of yearly deaths worldwide can be attributed to alcohol use (WHO, 2011). In the United States, health care-related costs because of alcoholism surpass those of cancer and obesity (CASA, 2000). Alcohol and tobacco co-abuse is common. Nicotine-dependent smokers are four times more likely to be diagnosed with alcohol abuse disorders than nonsmokers, and alcohol-dependent individuals are three times more likely to smoke (Grant et al, 2004).

One possible explanation for the high rate of co-abuse is the ability of both alcohol and nicotine to enhance the rewarding properties of each other. Acute, simultaneous coexposure to ethanol and nicotine produces an additive effect on dopamine release within the nucleus accumbens (NAc) (Tizabi et al, 2007). Interestingly, if nicotine exposure occurs first, the dynamics of dopamine signaling in response

\footnotetext{
*Correspondence: Professor M De Biasi, Department of Psychiatry, Perelman School of Medicine at the University of Pennsylvania, 4I5 Curie Boulevard, CRB-217, Philadelphia, PA 19104, USA, Tel: + I 2158989579 , Fax: + I 2155730833 ,

E-mail: marielde@mail.med.upenn.edu

Received I4 November 2014; revised II March 2015; accepted 12

March 20I5; accepted article preview online 19 March 2015
}

to ethanol change. Nicotine preexposure produces a blunted dopamine signal that leads to an increase in ethanol selfadministration, suggesting that the interaction between nicotine and ethanol is time dependent (Doyon et al, 2013a). In addition to altering reward responses, nicotine and ethanol coadministration in rodents leads to crosstolerance and cross-cravings (Collins et al, 1988). This phenomenon is also observed in humans, as alcohol dependence correlates with an increase in the number of cigarettes smoked and cigarette craving (Burton and Tiffany, 1997; Dawson, 2000; Henningfield et al, 1984). Finally, coabuse of nicotine and alcohol might be maintained by the ability of one drug to reduce the aversive properties of the other. For example, smoking partially improves the cognitive deficits caused by drinking (Ceballos, 2006). The literature in humans is complemented by numerous preclinical studies that point to the involvement of the nicotinic cholinergic system in alcohol abuse (Chatterjee and Bartlett, 2010; Rahman et al, 2014).

Some of the symptoms produced by abstinence from alcohol or nicotine are very similar, suggesting some overlap in the circuits and the molecular mechanisms involved in the manifestations of withdrawal (Hughes et al, 1994; Saitz, 1998). In support of this notion, upon cessation of both nicotine and ethanol, acetylcholine levels increase and 
dopamine levels decrease in the NAc. In addition, varenicline, a partial nicotinic acetylcholine receptor (nAChR) agonist used for nicotine cessation therapy, may reduce alcohol consumption in heavy smokers (Erwin and Slaton, 2014; Litten et al, 2013; Ray et al, 2014), further underscoring the role of nAChRs in the mechanisms of alcohol addiction (Chatterjee and Bartlett, 2010; Rahman et al, 2014). Moreover, brain areas that have been shown to regulate affective behavior and nicotine withdrawal symptoms are possible candidate regions for regulating the emergence of withdrawal-associated behaviors after ethanol cessation.

The overall goal of this study was to evaluate the role of nAChRs in the physical manifestations of ethanol withdrawal and to determine whether, and how, nicotine co-abuse affects alcohol withdrawal symptoms. In addition, we utilized intracranial injections of a $\mathrm{nAChR}$ antagonist to examine the role of the medial habenula $(\mathrm{MHb})$ and interpeduncular nucleus (IPN) during withdrawal from ethanol alone, or nicotine and ethanol coadministration.

\section{MATERIALS AND METHODS}

\section{Animals}

We examined 2- to 6-month-old male and female C57BL/6J mice. Weaning occurred 21 days after birth and same-sex littermates were housed in cages containing a maximum of five animals with ad libitum access to food pellets (Labdiet 5001, PMI, Brentwood, MO) and water. Mice were housed in a 12-h light/dark cycle, temperature-controlled room $\left(24 \pm 2{ }^{\circ} \mathrm{C}\right.$, relative humidity $\left.55 \pm 10 \%\right)$. All behavioral testing occurred during the light cycle. All procedures were approved by the institutional animal care and use committee and followed the guidelines for animal intramural research from the National Institute of Health.

\section{Chronic Alcohol Treatment}

Mice received a chronic ethanol treatment that has been successfully utilized to induce ethanol withdrawal symptoms upon treatment cessation (Farook et al, 2007). Briefly, mice were injected daily with either $2 \mathrm{~g} / \mathrm{kg}(20 \% \mathrm{w} / \mathrm{v})$ ethanol or saline for a minimum of 9 days. Both solutions contained $9 \mathrm{mg} / \mathrm{kg}$ of the alcohol dehydrogenase inhibitor 4-methylpyrazole (4MP, Sigma-Aldrich, St Louis, MO) to prolong the half-life of plasma ethanol (Farook et al, 2007; Perez and De Biasi, 2015).

\section{Nicotine and Ethanol Cotreatment}

Mice were treated by adding nicotine $(200 \mu \mathrm{l} / \mathrm{ml}$, SigmaAldrich) into the drinking water for 6 weeks. In the drinking water of treatment and control groups, $2 \%$ saccharine was added (to mask the bitter flavor of nicotine) (Salas et al, 2009; Sparks and Pauly, 1999; Zhang et al, 2012). In coadministration experiments, mice received ethanol or control injections during the last 10 days of nicotine treatment. Mice were injected with ethanol intraperitoneally (i.p.) because of reported pharmacokinetic interactions that lead to reduced ethanol plasma levels during simultaneous oral exposure to ethanol and nicotine (Chen and Harle, 2005). This effect was suggested to be due to a nicotine-induced delay in gastric emptying (Chen and Harle, 2005) that favors increased ethanol metabolism by the gastric enzyme alcohol dehydrogenase. This nicotine-ethanol interaction had been reported earlier, but those authors concluded that it was not based on pharmacokinetics as nicotine does not seem to affect the elimination rate of ethanol and vice versa (Collins et al, 1988).

Blood ethanol concentrations (BECs) were measured in controls and mice chronically treated with nicotine. Whole trunk blood samples were taken 1,4 , and $6 \mathrm{~h}$ after ethanol injections. Blood plasma was analyzed using a colorimetric ethanol assay kit from Sigma-Aldrich (MAK076). No significant changes in BECs were observed between control-treated and nicotine-treated mice at any time point. Similar to what has been previously reported (Perez and De Biasi, 2015; Sparks and Pauly, 1999), BECs were $168.3 \mathrm{mg} / \mathrm{dl}(\mathrm{STE} \pm 12.8$ $n=8)$ at $1 \mathrm{~h}$ after ethanol injections and such alcohol plasma levels were decreased by 50 and $84 \%$ at 4 and $6 \mathrm{~h}$ after ethanol treatment, respectively.

\section{Surgical Procedure for Brain Cannulation}

Animals were anesthetized with isoflurane and stereotactically implanted with a bilateral or unilateral cannula guide (26 G, Plastics One Roanoke, VA) into MHb, IPN, or control areas. The coordinates used for cannula placement were as follows from bregma: $\mathrm{MHb}$, anterior/posterior (AP) -0.17 medial/lateral $(\mathrm{ML}) \pm 0.025$, dorsal/ventral $(\mathrm{DV})-0.27$; IPN, $20^{\circ}$ angle, $\mathrm{AP}-0.36, \mathrm{ML}+0.17, \mathrm{DV}-0.49$; hippocampal control, $10^{\circ}$ angle, $\mathrm{AP}-0.2, \mathrm{ML} \pm 0.17, \mathrm{DV}-0.2$; ventral tegmental area (VTA) control, $10^{\circ}$ angle, AP - 0.36, ML $\pm 0.16-0.2$, DV 0.46 (Salas et al, 2009). Three holes were drilled for placement of small anchoring screws ( $>0.8 \mathrm{~mm}$ diameter) and the cannula base was secured with dental cement (Stoelting, Wood Dale, IL). A dummy cannula, which was removed upon testing, was inserted into the cannula guide. At the end of each experiment, cannula placement was verified by a microinjection of $0.5 \mu \mathrm{l}$ methylene blue, as previously described (Salas et al, 2009).

\section{Spontaneous Withdrawal Testing}

Single-drug treatment. At $24 \mathrm{~h}$ after the last ethanol injection or nicotine deprivation, mice were placed in a cage and monitored for $20 \mathrm{~min}$. The occurrence of the following physical (also called somatic) signs was noted: shaking, scratching, grooming, paw tremors, chewing, ptosis, vocalizations, tail rattling, cage scratching, and writhing behaviors, and the sum of all physical signs was used for comparisons (Economidou et al, 2011; Majchrowicz, 1975; Salas et al, 2004; Salas et al, 2009). A small subset of animals received either an acute injection of $1 \mathrm{~g} / \mathrm{kg}$ ethanol $1 \mathrm{~h}$ before testing or $0.3 \mathrm{mg} / \mathrm{kg}$ nicotine $10 \mathrm{~min}$ before testing.

Drug cotreatment. Analysis of withdrawal behavior in mice cotreated with nicotine and ethanol was similar to that conducted in mice under single ethanol or nicotine treatment. Testing took place over the course of 4 days. To examine spontaneous withdrawal, mice were injected with ethanol, and nicotine water was replaced with control water. Physical signs were monitored for $20 \mathrm{~min}$ at $4,24,48$, and $72 \mathrm{~h}$ after ethanol and nicotine cessation. In some experiments, 
cotreated mice were kept on either nicotine or ethanol, whereas the other drug was withdrawn. This was achieved by continuing access to nicotine water or injecting ethanol daily, $4 \mathrm{~h}$ before testing. A comprehensive table diagramming all the specific drug treatments and withdrawal scenarios can be found in Supplementary Table 1.

\section{Mecamylamine-Precipitated Withdrawal}

We used mecamylamine (Sigma-Aldrich), a nonselective nicotinic receptor antagonist, to precipitate withdrawal in mice treated with ethanol. Physical signs were monitored for $20 \mathrm{~min}$ at $3.5 \mathrm{~h}$ after the last ethanol treatment, after which mice received an i.p. injection of $1 \mathrm{mg} / \mathrm{kg}$ mecamylamine (Sigma-Aldrich) and were again observed (20 min), $10 \mathrm{~min}$ later, for changes in physical signs. To determine the doseresponse relationships for mecamylamine, a subset of mice was treated with either ethanol, nicotine, or both nicotine and ethanol, and various doses of mecamylamine $(0,1,2$, and $3 \mathrm{mg} / \mathrm{kg}$ ) were used to precipitate withdrawal.

\section{Testing of Locomotor Behavior}

The open field arena (OFA) was used as a behavioral task to measure locomotor behavior. Briefly, mice were tested in the OFA $(40 \mathrm{~cm} \times 40 \mathrm{~cm} \times 40 \mathrm{~cm})$ for $30 \mathrm{~min}$ while the computer automated software AnyMaze (Stoelting) tracked the movement of the mouse throughout the apparatus. To measure the effect of mecamylamine administration on locomotor behavior, drug-naive mice received a series of increasing mecamylamine doses before being placed in the OFA. The OFA was also used to measure the effect of acute nicotine or ethanol on locomotion in mice chronically treated with ethanol or nicotine, respectively. In the nicotine treatment group, mice received an injection of $1 \mathrm{~g} / \mathrm{kg}$ ethanol $1 \mathrm{~h}$ before testing in the OFA. In the chronic ethanol treatment group, mice received an i.p. injection of $0.3 \mathrm{mg} / \mathrm{kg}$ nicotine $10 \mathrm{~min}$ before being placed in the apparatus.

\section{Intracranial Infusions of Mecamylamine}

Mice were treated with ethanol only, or nicotine plus ethanol, as described above. At 3 days before testing, mice were implanted with chronic cannulae directed toward $\mathrm{MHb}$, IPN, hippocampus (Hippo), or VTA. On testing day, mice received a microinfusion of $0.5 \mu \mathrm{l}$ of either saline or mecamylamine $(2 \mu \mathrm{g} / \mu \mathrm{l})$ over the time course of $3 \mathrm{~min}$, at a rate of $0.25 \mu \mathrm{l} / \mathrm{min}$ (Salas et al, 2009). Mice were then placed into a home cage and $10 \mathrm{~min}$ later were monitored for changes in physical signs. For ethanol-only-treated mice, microinjections occurred $4 \mathrm{~h}$ after ethanol injection. For cotreated mice, chronic cannulae were implanted toward the $\mathrm{MHb}$ or the IPN 3 days before testing. Microinjections occurred $4,24,48$, and $72 \mathrm{~h}$ after either ethanol or nicotine cessation.

\section{Data Analysis and Statistics}

Data were examined by Student's $t$-test or ANOVA. When appropriate, ANOVA with repeated measures was used. The Newman-Keuls post hoc test was used for specific comparisons.

\section{RESULTS}

\section{Mecamylamine Precipitates Physical Signs of Ethanol Withdrawal}

Treatment with daily ethanol injections produced a significant increase in physical signs $24 \mathrm{~h}$ after ethanol cessation (Figure 1a, Student's $t$-test $p<0.001$ ). The increase in physical signs during withdrawal was similar to what our $\mathrm{lab}$ and others have described in nicotine-treated mice during both spontaneous and mecamylamine-precipitated withdrawal (Salas et al, 2004; Salas et al, 2009). Therefore, we hypothesized that shared molecular mechanisms might underlie the physical manifestations of ethanol and nicotine withdrawal. In order to test this hypothesis, ethanol and control-treated mice received an i.p. injection of the nonselective nicotinic receptor antagonist mecamylamine (1 mg/ $\mathrm{kg}$ ) to precipitate physical signs of withdrawal. Mecamylamine injections produced a significant increase in somatic signs exclusively in ethanol-treated mice (Figure 1b), resulting in a significant treatment $\times$ mecamylamine interaction $(F(1,10)=12.564, p=0.005)$. Overall, these data suggest that nAChRs modulate some of the physical manifestations of ethanol withdrawal.

We then proceeded to compare the effects of mecamylamine over a range of doses. For this experiment, a group of mice received either nicotine in the drinking water or ethanol injections. Over the course of several days, mice were injected with various mecamylamine doses $(0,1,2$, or $3 \mathrm{mg} / \mathrm{kg})$ and tested for changes in somatic signs. On the final day of testing, physical signs were observed during spontaneous withdrawal from the respective treatment. An ANOVA with repeated measures was used to analyze the data and demonstrated a significant interaction between drug and mecamylamine doses $(F(3,30)=173.522, p<0.001$; Figure $1 c)$. Both ethanol- and nicotine-treated mice had significant increases in somatic signs after mecamylamine. However, ethanol-treated mice were more sensitive to mecamylamine injection, displaying increased somatic signs at $1 \mathrm{mg} / \mathrm{kg}$ mecamylamine and significantly more signs than nicotinetreated mice at $2 \mathrm{mg} / \mathrm{kg}$. At a dose of $3 \mathrm{mg} / \mathrm{kg}$ mecamylamine, ethanol-treated mice became extremely sedated, making it difficult to observe changes in physical signs. To explore the potential sedative properties of mecamylamine, we conducted a control experiment and showed that when drug-naive mice are tested in the OFA, mecamylamine alone does not produce sedation or hypolocomotion, even at a dose as high as $10 \mathrm{mg} / \mathrm{kg}(\mathrm{F}(3,18)=0.719, p=0.554$; Supplementary Figure 1). Nicotine-treated mice showed significant increases in somatic signs beginning at a dose of $2 \mathrm{mg} / \mathrm{kg}$ mecamylamine (Figure 1c). Interestingly, during spontaneous withdrawal, ethanol and nicotine withdrawal led to comparable signs of withdrawal $(\mathrm{F}(1,10)=0.986, p=3.44$; Figure 1d).

\section{Microinjection of Mecamylamine into MHb and IPN are Sufficient to Precipitate the Physical Signs of Ethanol Withdrawal}

Our lab has previously highlighted the role of nAChRs in $\mathrm{MHb}$ and IPN in mediating physical symptoms of nicotine withdrawal (Salas et al, 2009). As antagonism of nAChRs can precipitate physical signs of withdrawal in ethanol-treated 

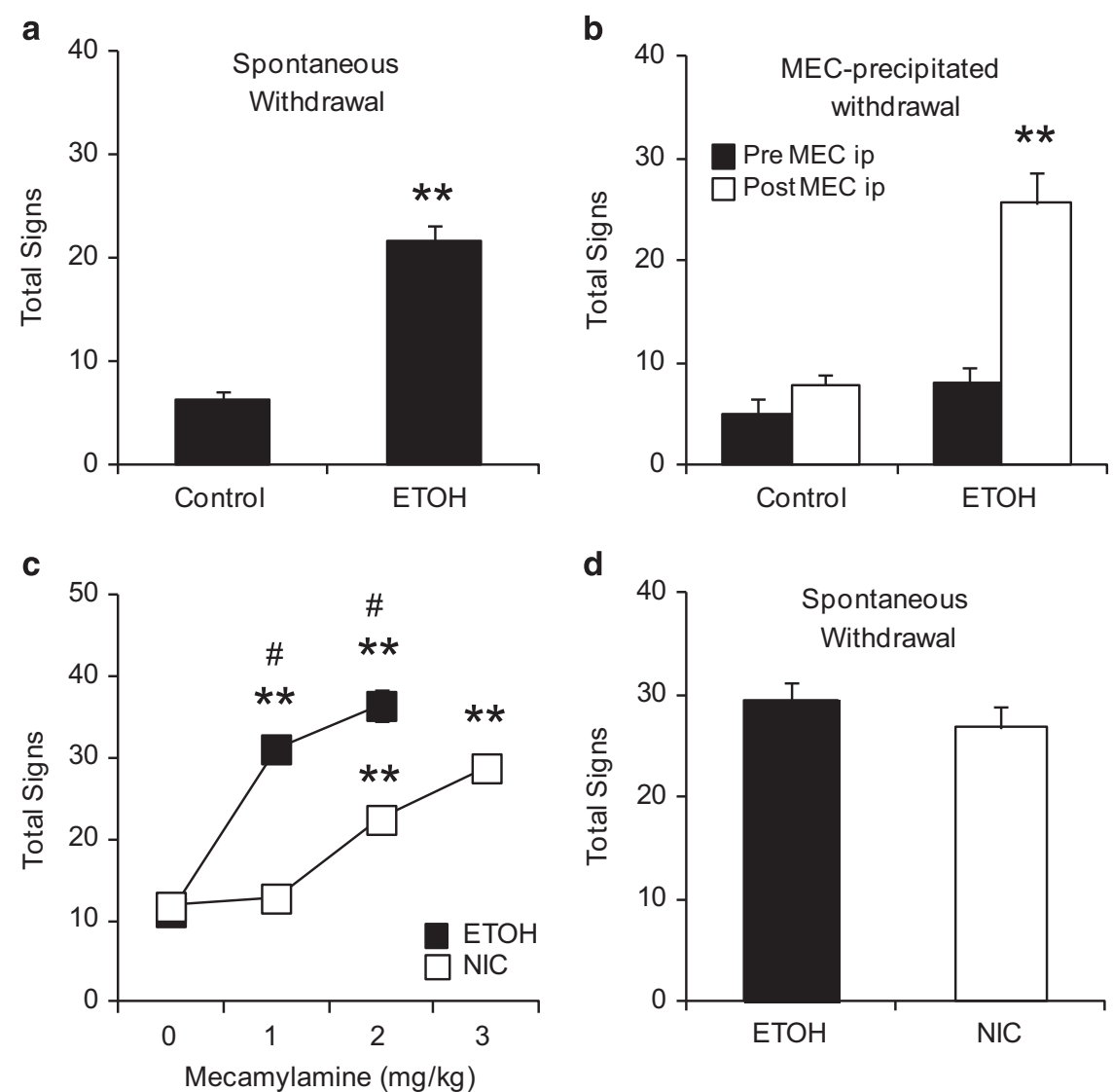

Figure I nAChRs modulate physical signs of ethanol withdrawal. (a, b) Control- and ethanol (ETOH)-treated mice were tested for changes in physical signs during spontaneous (a) or mecamylamine-precipitated withdrawal (MEC, b). Only ethanol-treated mice displayed significant increases in physical signs. (c, d) Mice were treated with either ethanol injections or nicotine $(\mathrm{NIC})$ in their drinking water. Physical signs were measured following various doses of the nicotinic receptor antagonist, mecamylamine (c) or during spontaneous withdrawal (d). Although ethanol-treated mice were more sensitive to the effects of mecamylamine (c), during spontaneous withdrawal they exhibited symptoms similar to those observed in nicotine-withdrawing mice (d). Animal numbers are as follows: (a) 8 per experimental group; (b) 5 Control, $7 \mathrm{ETOH}$; (c, d) 6 per experimental group. ** $P>0.01$ compared with control and Mec (0) group, \#p $>0.01$ compared with NIC at same dose.

mice, we tested the hypothesis that MHb and IPN also participate in the mechanisms of ethanol withdrawal. On ethanol treatment day 7 , mice were implanted with cannulae directed to the MHb, IPN, Hippo, or VTA. On testing day 1 , $4 \mathrm{~h}$ after the last ethanol injection, mice received an intracranial infusion of saline or mecamylamine $(1 \mu \mathrm{g})$, and 10 min later were examined for the emergence of physical signs. The following day, mice were again treated with ethanol, and $4 \mathrm{~h}$ later received the opposite treatment. For example, mice that received saline on the first day of testing received mecamylamine the following day and vice versa. Only mice verified for correct site infusions were used for analysis (see Supplementary Figure 2 for the location of individual injections).

Infusions of mecamylamine into either $\mathrm{MHb}$ or IPN produced similar results (Figure $2 \mathrm{a}$ and $\mathrm{b}$ ). An ANOVA with repeated measures was used to analyze data for each site individually. For both MHb and IPN there was a significant interaction between ethanol treatment and microinjection $\left(\mathrm{F}_{\mathrm{MHb}}(1,12)=15.588, p=0.002 ; \mathrm{F}_{\mathrm{IPN}}(1,19)=25.086, p<0.001\right)$. In ethanol-treated mice, antagonism of nAChRs in the $\mathrm{MHb}$ or IPN significantly increased the total number of physical signs displayed. Saline injections had no effect in either ethanol- or control-treated animals. Infusions into Hippo and VTA were used as control sites and analyzed together. Mice used for control sites were all treated with ethanol. Hippo and VTA were chosen as control sites because these two brain areas express nAChRs that have been shown to modulate nicotine and morphine withdrawal (Muldoon et al, 2014; Salas et al, 2009). In addition, we previously used Hippo and VTA as control sites for the MHb and IPN, respectively, to examine mecamylamine-precipitated nicotine withdrawal (Salas et al, 2009). Mecamylamine had no effect in either of the control area $\left(\mathrm{F}_{\text {Site } \times \text { Infusion }}(1,9)=0.112\right.$, $p=0.745$, Figure 2c).

\section{Continued Exposure to Either Nicotine or Ethanol Is Sufficient to Prevent Withdrawal in Ethanol/Nicotine Cotreated Mice}

Given the potential influence of nAChRs on the physical symptoms of ethanol withdrawal, we investigated how coexposure to nicotine and ethanol would affect the emergence of withdrawal symptoms. Mice were treated with no drug, nicotine only, ethanol only, or both nicotine and ethanol. As anticipated, mice receiving nicotine-only or ethanol-only 

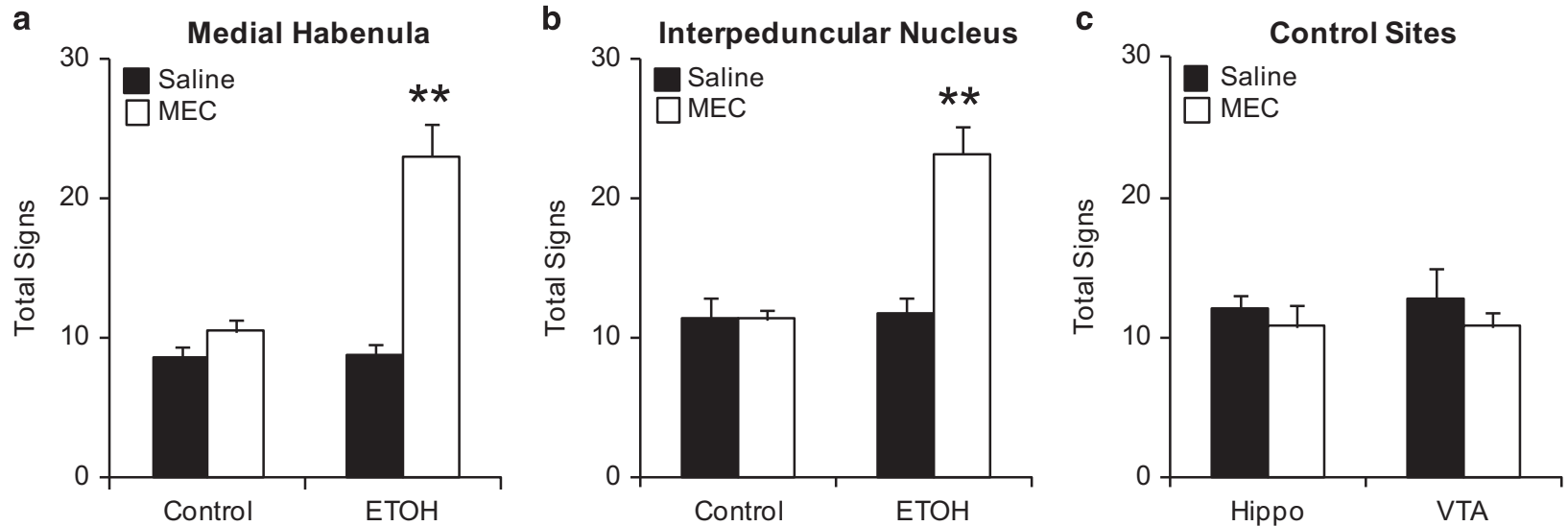

Figure $2 \mathrm{MHb}$ and IPN, but not hippocampus or VTA, play a role in modulating physical signs of ethanol withdrawal. (a, b) Mice treated with either control or ethanol $(E T O H)$ injections received saline or mecamylamine (MEC) infusions into either MHB or IPN. Physical signs increased significantly after mecamylamine infusions only in mice treated with ethanol. (c) Hippocampus (Hippo)- and VTA-cannulated mice were treated with ethanol and received infusions of saline or mecamylamine. Physical signs did not increase after mecamylamine treatment in these experimental subjects. Animal numbers are as follows: (a) 5 Controls and $9 \mathrm{ETOH}$; (b) 8 Controls and $13 \mathrm{ETOH}$; (c) 6 Hippo and 5 VTA. **P $<0.0$ I compared with all groups.

exhibited a significant increase in the number of physical signs $24 \mathrm{~h}$ after drug cessation (Figure 3a). By $48 \mathrm{~h}$, somatic signs had significantly subsided, although they were still significantly different from the signs observed $4 \mathrm{~h}$ after drug cessation and in no-drug, control mice. In contrast, simultaneous withdrawal produced a physical syndrome that began at $24 \mathrm{~h}$ and persisted up to at least $72 \mathrm{~h}$ after drug cessation. When compared with single-drug-treated, somatic signs at $24 \mathrm{~h}$ were attenuated but later time points were significantly higher than those of single-substance-treated mice. Overall, when compared with single-drug-treated mice, simultaneous withdrawal from nicotine and ethanol produced a significant difference in severity and overall time course of physical signs $\left(\mathrm{F}_{\mathrm{Nic} \times \mathrm{ETOH} \times \operatorname{Time}}(3,120)=73.326\right.$, $p<0.001$ ).

The high occurrence of smoking in alcohol-dependent individuals suggests that the use of one drug fosters and maintains the abuse of the other. Therefore, we hypothesized that continued use of one of the two drugs would be sufficient to alleviate withdrawal symptoms from the other. Cotreated mice were tested for withdrawal from either nicotine or ethanol (Figure 3b). Continued use of either one of the two drugs attenuated the emergence of physical symptoms up to $72 \mathrm{~h}(\mathrm{~F}(1,13)=6.139, p=0.946)$. Given that continued exposure to either nicotine or ethanol is sufficient to prevent the expression of physical signs of withdrawal in cotreated mice, we wanted to test whether previous exposure to both alcohol and nicotine was required. Mice chronically treated with either ethanol only or nicotine only were examined for withdrawal signs. Subsequently, they were retested after receiving acute injections of either nicotine (ethanol treated) or ethanol (nicotine treated). Acute administration of either nicotine (Figure $3 c, \mathrm{~F}_{\text {Treatment }} \times$ Acute Inj $(1,35)=$ $32.265, p<0.001$ ) or ethanol (Figure $3 \mathrm{~d}^{\mathrm{F}} \mathrm{F}_{\text {Treatment } \times \text { Acute Inj }}$ $(1,30)=29.973, p<0.001)$ was sufficient to attenuate withdrawal symptoms. It should be noted that the doses of nicotine $(0.3 \mathrm{mg} / \mathrm{kg}, 10 \mathrm{~min}$ before testing) and ethanol $(1 \mathrm{~g} / \mathrm{kg}, 1 \mathrm{~h}$ before testing) used did not produce any changes in locomotor activity when tested in the OFA (not shown).
Acute ethanol and nicotine had no effect in control mice (Supplementary Figure 3A and B).

\section{Nicotinic Receptors in MHb and IPN Influence Withdrawal in Cotreated Mice}

Based on the results obtained in ethanol-only-treated mice, we further explored how nAChRs influence withdrawal in ethanol/nicotine cotreated mice. First, withdrawal was precipitated by i.p. injections of mecamylamine $(0,1,2$, or $3 \mathrm{mg} / \mathrm{kg}$ ) at $4 \mathrm{~h}$ after ethanol treatment (Figure $4 \mathrm{a}$ ), whereas mice had access to nicotine up to testing. Compared with a no-drug control group, mecamylamine triggered withdrawal at 2 and $3 \mathrm{mg} / \mathrm{kg} \quad\left(F_{\text {Drug } \times \text { Time }}(1,30)=22.892, p<0.001\right)$. Interestingly, unlike what was observed in ethanol-onlytreated mice, cotreated mice did not exhibit increased sensitivity to the effects of mecamylamine. In fact, withdrawal symptomatology was similar to that observed during nicotine-only withdrawal (Figure 1c).

Given that the MHb/IPN circuit has a major influence on the physical symptoms of nicotine and ethanol withdrawal, we tested whether nAChRs within the MHb and the IPN also influence withdrawal during codependence. As we found that intra-Hippo and intra-VTA mecamylamine injections did not precipitate somatic signs during ethanol-only or nicotine-only withdrawal (Salas et al, 2009), we focused our experiments on $\mathrm{MHb}$ and IPN. Cotreated mice underwent ethanol-only, nicotine-only, or simultaneous nicotine and ethanol withdrawal. Mice received microinjections of saline 4,24 , and $72 \mathrm{~h}$ after drug cessation, whereas mecamylamine was injected $48 \mathrm{~h}$ after drug removal. Only mice verified for correct infusion site were used for analysis (Supplementary Figure 4).

Saline microinjections into either MHb (Figure 4b) or IPN (Figure 4c) had no effect in mice from the no-drug group or those withdrawn from both nicotine and ethanol. Saline microinjections also had no effect in MHb and IPN implanted mice that kept receiving one drug while withdrawing from the other. Mecamylamine infusion in either 
a
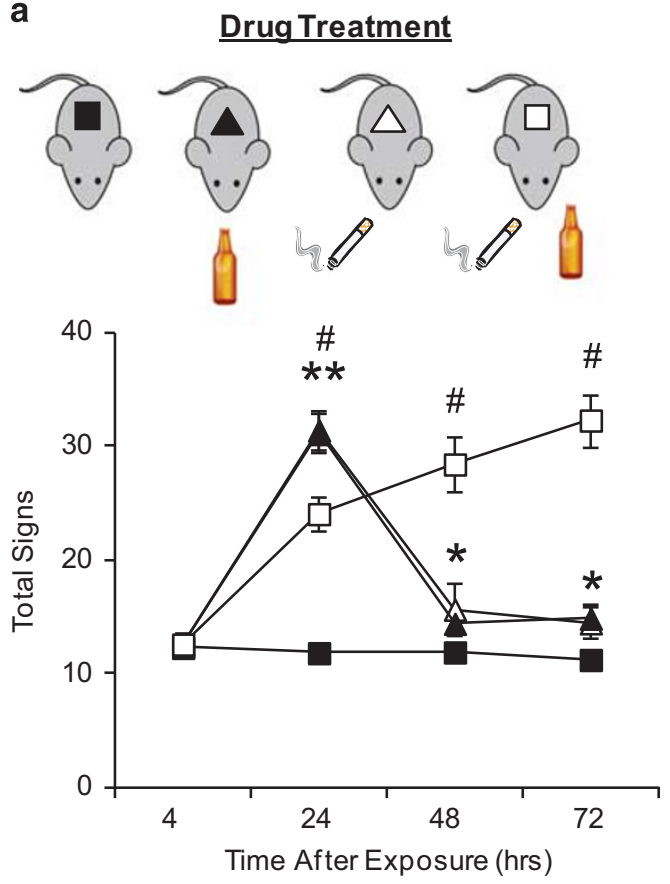

C

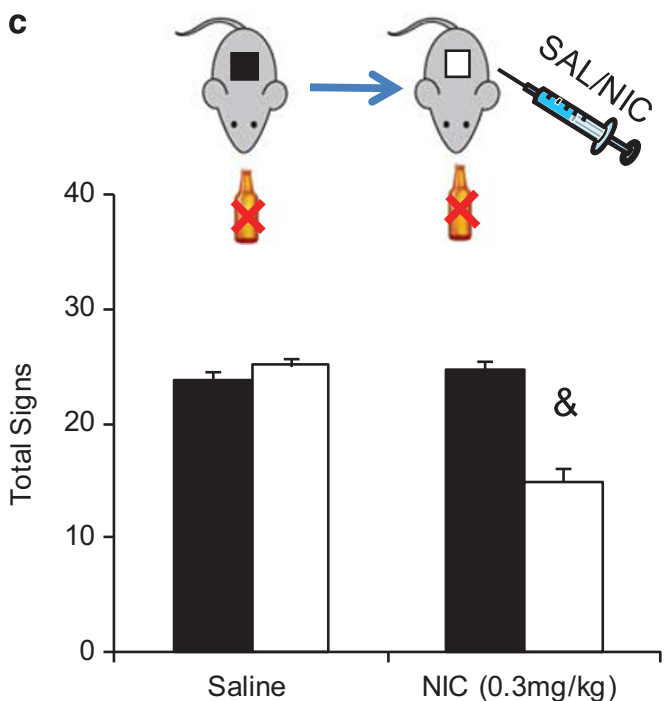

b
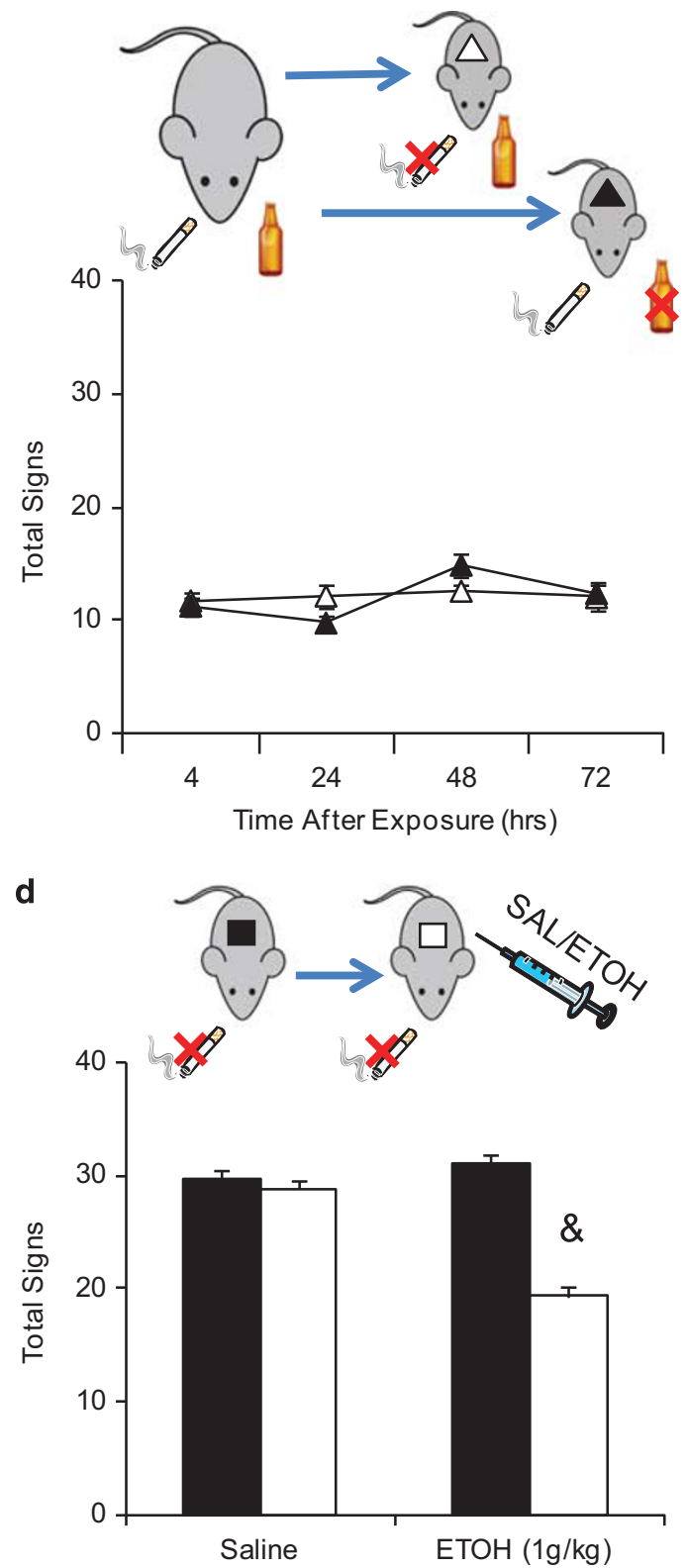

Figure 3 In codependent mice, simultaneous withdrawal produces long-lasting symptoms that are attenuated by continued exposure to either nicotine or ethanol. (a) Mice were treated with either control, ethanol (ETOH), nicotine (NIC), or both. Physical signs were observed 4, 24, 48, and 72 $\mathrm{h}$ after drug cessation. All drug groups exhibited increases in signs at $24 \mathrm{~h}$, but only simultaneous withdrawal of ethanol and nicotine produced sustained symptoms that persisted at least for $72 \mathrm{~h}$ after treatment. (b). Cotreated mice underwent ethanol-only or nicotine-only withdrawal. Continued exposure to at least one drug protected against the emergence of somatic signs during withdrawal. (c, d) Mice treated with either chronic ethanol only (c) or chronic nicotine only (d) were observed for changes in physical signs during spontaneous withdrawal. Mice were then treated with an acute administration of either saline, $0.3 \mathrm{mg} / \mathrm{kg}$ nicotine (c), or I g/kg ethanol (d), and physical signs were reevaluated. Before acute injections, mice undergoing withdrawal exhibited significant physical signs that were decreased after either alcohol or nicotine treatment. Animal numbers are as follows: (a) I 5 no drug, IO NIC, I I ETOH, and 8 cotreated; (b) 7 NIC and $8 \mathrm{ETOH}$; (c) IO Saline and $9 \mathrm{NIC}$; (d) IO Saline and $7 \mathrm{ETOH}$. $* P<0.05, * * P<0.01$ compared to control; ${ }^{\#} p<0.0$ I cotreated compared with control and single treatment; ${ }^{\&} p<0.01$ compared with preinjection.

MHb or IPN did not produce further increases of physical signs in mice undergoing simultaneous withdrawal. In cotreated mice that had continued access to at least one drug, intra-MHb infusions of $1 \mu \mathrm{g}$ mecamylamine were sufficient to precipitate withdrawal (Figure $4 \mathrm{~b} ; \mathrm{F}_{\text {Treatment }} \times$ Infusion $(9,57)=14.011, p<0.001)$. Similarly, a microinfusion of $1 \mu \mathrm{g}$ mecamylamine in the IPN was able to precipitate withdrawal signs in mice with either continued nicotine or ethanol treatment $\left(\mathrm{F}_{\text {Treatment } \times \text { Microinjection }}(9,69)=10.322, p<0.001\right.$, Figure 4c). Overall, the results suggest that withdrawal from nicotine and ethanol coexposure is influenced by the $\mathrm{MHb} / \mathrm{IPN}$ circuit. 


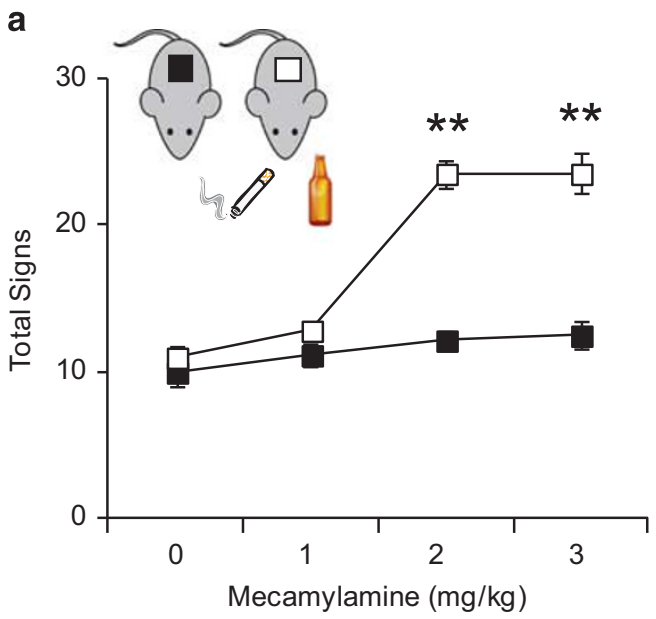

b

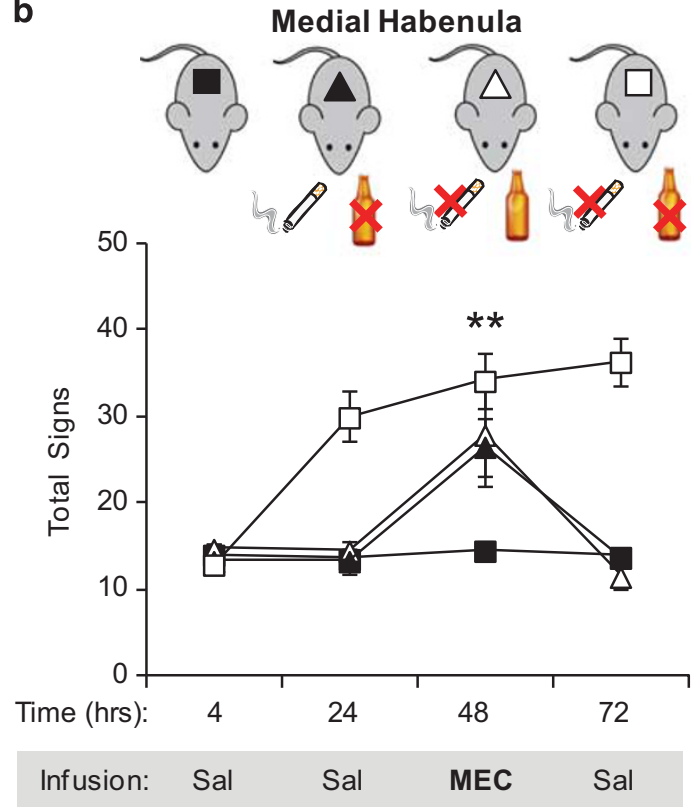

C

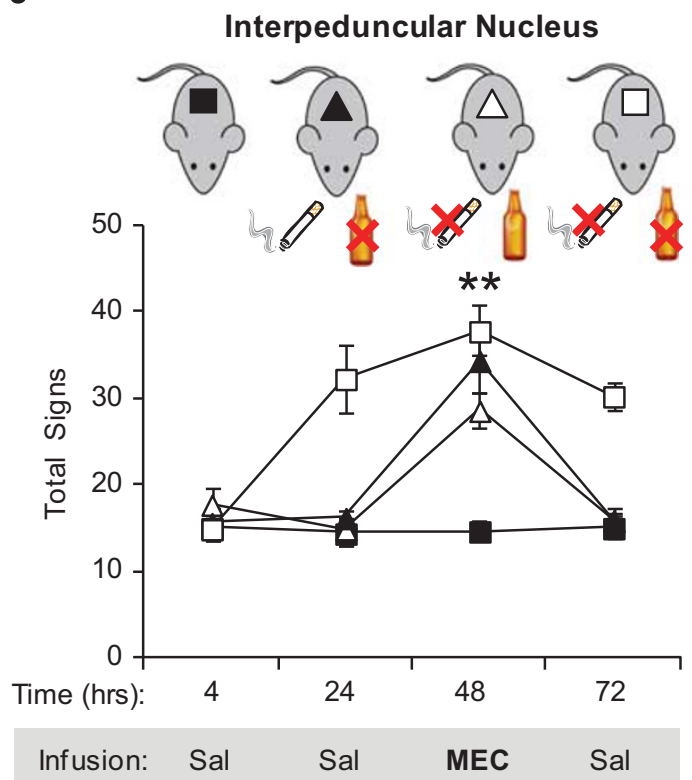

Figure $4 \mathrm{nAChRs}$ within the MHb and the IPN influence withdrawal symptoms in mice cotreated with nicotine and ethanol. All mice were either injected with saline and drank water with saccharin or received ethanol (ETOH) injections and nicotine (NIC) in the drinking water. (a) Mice received i.p. injections of mecamylamine at various doses to precipitate withdrawal. Physical signs increased significantly only after 2 and $3 \mathrm{mg} / \mathrm{kg}$ mecamylamine. (b, c) Mice underwent the following withdrawal scenarios: ethanol only, nicotine only, or simultaneous withdrawal from both nicotine and ethanol. Mice received saline infusions into MHb (b) or IPN (c) at 4, 24, and $72 \mathrm{~h}$ after drug cessation. A physical withdrawal syndrome was precipitated with mecamylamine (I $\mu \mathrm{g})$ at $48 \mathrm{~h}$. The $\mathrm{nAChR}$ antagonist triggered withdrawal symptoms in the asymptomatic animals allowed access to one drug during withdrawal from the other. Mecamylamine had no effect on control mice and did not exacerbate withdrawal symptoms in mice undergoing withdrawal from both nicotine and ethanol. Animal numbers are as follows: (a) 6 per experimental group; (b) 8 Control, $5 \mathrm{NIC}, 5 \mathrm{ETOH}$, and 5 both; (c) 8 Control, $6 \mathrm{NIC}, 7 \mathrm{ETOH}$, and 6 both. *** $<0.0$ l compared with no-drug control.

\section{DISCUSSION}

The high occurrence of alcohol and tobacco co-abuse suggests that nicotine and alcohol share common mechanisms throughout the addiction process (Dani and Harris, 2005; Doyon et al, 2013b; Hurley et al, 2012; Rahman et al, 2014). Understanding the mechanisms of interaction between the two drugs has direct relevance for cessation strategies and treatment outcomes for alcoholics who are also addicted to nicotine. A subset of alcoholics undergoing treatment for alcohol abuse reported that smoking helped them cope with the urge to drink (Asher et al, 2003; Gulliver et al, 1995; Kalman et al, 2001), suggesting that nicotine may attenuate the negative emotional and physical states that emerge during ethanol withdrawal. This study examined the pharmacological and circuit-level mechanisms underlying the physical symptoms of withdrawal.

As previously reported by us and others (Economidou et al, 2011; Majchrowicz, 1975; Perez and De Biasi, 2015), we confirmed that ethanol withdrawal has a physical component. Physical symptoms were detected upon spontaneous, nondrug-induced withdrawal from ethanol and were similar to those observed during spontaneous withdrawal from nicotine. Physical signs could be precipitated in alcoholtreated mice by systemic injection of mecamylamine, a nAChR antagonist commonly used to study nicotine withdrawal (Salas et al, 2004; Salas et al, 2009). Surprisingly, mice treated with ethanol were more sensitive to the effects of 
mecamylamine than mice treated with nicotine. A dose of $1 \mathrm{mg} / \mathrm{kg}$ mecamylamine could trigger withdrawal symptoms in ethanol- but not nicotine-treated subjects, and $3 \mathrm{mg} / \mathrm{kg}$ mecamylamine induced sedation, an effect not observed in control mice injected with mecamylamine alone or when the drug was used to precipitate nicotine withdrawal. These results point to a direct involvement of the nicotinic cholinergic system in the mechanisms of ethanol withdrawal and suggest molecular adaptations that might differ for ethanol $v s$ nicotine abuse.

We then asked whether withdrawal symptoms would be different in mice cotreated with nicotine and ethanol. Our study suggests that simultaneous withdrawal from nicotine and ethanol differs from withdrawal from each individual drug. Physical signs are present significantly longer in mice undergoing simultaneous withdrawal from nicotine and ethanol. In rodents, physical signs peak within $12-48 \mathrm{~h}$ after drug cessation and then subside when treated with nicotine or ethanol individually (Hershon, 1977; Majchrowicz, 1975). However, in cotreated animals, symptoms continued to increase for at least $72 \mathrm{~h}$ after drug cessation. If cotreated mice were withdrawn from only one drug, withdrawal was attenuated, suggesting that one drug can mitigate the negative effects associated with withdrawal from the other. Such effect does not require chronic exposure to nicotine or ethanol, as acute nicotine administration in ethanol-treated mice (and vice versa) is sufficient to reduce physical signs of withdrawal.

When mecamylamine was used to precipitate withdrawal in cotreated mice, symptom intensity was similar to that observed in mice withdrawn from nicotine only and the increased sensitivity exhibited by ethanol-only-treated mice was no longer observed. Because all mice were treated with nicotine before ethanol cotreatment and had access to nicotine up to the testing time, it is possible that nAChR occupancy by nicotine may prevent the ethanol-mecamylamine interaction observed in ethanol-only-treated mice. Alternatively, the phenomenon might reflect cellular adaptations produced by chronic nicotine treatment.

Nicotine's ability to attenuate the negative emotional and physical states that emerge during ethanol withdrawal could be because of the ability of nicotine to normalize decreased dopamine levels associated with alcohol cessation. In the NAc, acute administration of either ethanol or nicotine causes an increase in dopamine release, in part because of activation of nAChRs in the VTA (Doyon et al, 2013b). Concurrent, acute administration of nicotine and ethanol produces a synergistic effect leading to dopamine release that is significantly higher than that produced by each drug individually (Tizabi et al, 2007). However, when nicotine administration precedes acute alcohol treatment, the ethanol-induced increases in dopamine release are attenuated and dopamine neuronal firing is suppressed in the VTA (Doyon et al, 2013a). Although the mechanisms underlying the acute interactions between alcohol and nicotine are being revealed (Doyon et al, 2013b), the effect of chronic nicotine treatment on ethanol-induced changes in dopamine levels and behavior needs further study.

Given the interactions of nicotine and alcohol on withdrawal behaviors, brain areas that have been shown to regulate affective behavior and withdrawal symptoms are possibly involved. $\mathrm{MHb}$ and IPN are among those candidate areas (Baldwin et al, 2011; Salas et al, 2009). We previously used local infusions of mecamylamine to identify $\mathrm{MHb}$ and IPN as brain structures that influence the manifestations of nicotine withdrawal (Salas et al, 2009). Mecamylamine infusions into MHB and IPN of ethanol-only-treated mice led to increased physical signs, suggesting that the MHb/IPN axis also plays a role in ethanol withdrawal. In cotreated mice, mecamylamine infusions into either $\mathrm{MHb}$ or IPN could also precipitate withdrawal in mice still exposed to one of the drugs. This suggests that nAChRs within the $\mathrm{MHb} /$ IPN axis are required in order for either nicotine or ethanol to be able to prevent the emergence of withdrawal symptoms during periods of abstinence from one of the two substances of abuse. Hence, nAChRs expressed within the MHb and IPN are potential targets for drug development.

Both $\mathrm{MHb}$ and IPN express nAChRs containing the subunits encoded by the CHRNA5-CHRNA3-CHRNB4 gene cluster. In humans, certain single-nucleotide polymorphisms within this gene cluster represent risk alleles for nicotine dependence (Berrettini and Doyle, 2012), whereas other polymorphisms may influence alcohol-related behaviors (Choquet et al, 2013; Hallfors et al, 2013; Joslyn et al, 2008; Wang et al, 2009). In rodents, $\alpha 5-, \alpha 3-$, and $\beta 4$-containing nAChRs influence the rewarding and aversive properties of nicotine (Fowler et al, 2011; Morel et al, 2013) and the symptoms accompanying its withdrawal (Jackson et al, 2013; Salas et al, 2004; Salas et al, 2009). As the present study also implicates MHB and IPN in ethanol withdrawal, it is tempting to speculate that $\mathrm{nAChRs}$ containing the $\alpha 5, \alpha 3$, and/or the $\beta 4$ subunits within these brain structures are responsible for the phenomenon we observed. This hypothesis is further substantiated by the fact that those receptor subunits may affect other ethanol-related behaviors (Gallego et al, 2012). As nAChRs comprising $\alpha 3, \beta 4$, and/or $\alpha 5$ subunits can partially modulate symptoms of abstinence from morphine (Muldoon et al, 2014; Rho and Glick, 1998), the $\mathrm{MHb} / \mathrm{IPN}$ axis could represent a common circuit for the expression of physical abstinence symptoms for various drugs of abuse.

Few studies have focused on the severity of withdrawal symptoms in patients simultaneously undergoing alcohol detoxification and smoking cessation. Most have focused on the overall outcome of long-term ethanol cessation. In a 2011 report, Jacques et al, (2011) recorded the withdrawal symptoms of patients hospitalized for alcohol detoxification that were simultaneously undergoing smoking cessation. Both smoking and nonsmoking patients received benzodiazepines, but smokers were not provided with any smoking cessation aid, including nicotine replacement therapy. Compared with nonsmoking patients, smokers displayed increased physical signs, such as higher blood pressure, and required higher doses of benzodiazepines. In addition, when assessed with the Clinical Institute Withdrawal Assessment of Alcohol Scale, smokers reported an increase in withdrawal symptoms that lasted a few days (Jacques et al, 2011). A different study of simultaneous nicotine and alcohol cessation showed that before a relapse event, subjects had increased smoking urges, decreased positive mood, and decreased confidence in the ability to resist the urge to smoke (Holt et al, 2012). Patients who relapsed to alcohol reported a recent relapse to smoking, as well as increased urges to smoke (Holt et al, 2012). The ability for a recent smoking relapse to trigger a subsequent alcohol relapse after 
concurrent alcohol and nicotine cessation is not surprising, as smoking has been shown to produce compulsive alcohol cravings (Dawson, 2000; Hillemacher et al, 2006).

The preclinical data we present and the human studies in the literature indicate that in alcoholics who are also addicted to nicotine, addressing both dependencies might help to achieve long-lasting abstinence from alcohol. Recent clinical trials have shown promising results in subjects treated with varenicline, an FDA-approved aid for smoking cessation. Alcohol-dependent individuals who received varenicline treatment reported a significant decrease in alcohol cravings and consumption when compared with placebo-treated controls (Erwin and Slaton, 2014; Litten et al, 2013; Ray et al, 2014). The exact mechanism underlying the ability of varenicline treatment to reduce alcohol consumption is not well understood as changes in alcohol consumption because of varenicline are independent of patients smoking status (Litten et al, 2013). Varenicline acts on a number of nAChRs including $\alpha 4 \beta 2, \alpha 3 \beta 4, \alpha 3 \beta 2$, and $\alpha 7$ - and $\alpha 6$-containing $\mathrm{nAChRs}$ (Mihalak et al, 2006). The $\beta 2$-containing nAChRs in particular, which regulate nicotine intake in rodents (Picciotto et al, 1998), have been hypothesized to be involved in ethanol consumption. However, varenicline treatment is still able to decrease alcohol consumption in mice null for the $\beta 2 \mathrm{nAChR}$ subunit, suggesting that this receptor is not modulating varenicline-induced decreases in ethanol consumption (Kamens et al, 2010). Genetic and pharmaceutical studies in mice suggest that nAChRs composed of $\alpha 3 \beta 4$ and/ or $\alpha 5$ are likely candidates for the modulation of alcohol consumption (Chatterjee et al, 2011; Gallego et al, 2012). However, it should also be noted that polymorphisms in CHRNB3 and CHRNA6 (which encode the $\beta 3$ and $\alpha 6$ nAChR subunits) seem to correlate with alcohol consumption (Hoft et al, 2009) and nicotine dependence (Zhu et al, 2014). In addition, selective blockade of $\alpha 6$ - or $\beta 3$-containing receptors decreases alcohol consumption in rats (Kuzmin et al, 2009). Therefore, drugs that act on nAChRs might be useful in alcohol-nicotine codependence because of their potential effects on both alcohol consumption and withdrawal symptoms.

In summary, the present study addressed the mechanisms underlying the physical symptoms associated with ethanol withdrawal and identified the contributions of nicotinic cholinergic mechanisms within the $\mathrm{MHb} / \mathrm{IPN}$ axis. The results suggest that an antagonist selective for the nAChRs expressed within the MHb/IPN axis might help in the acute phase of abstinence from alcohol abuse. Further studies are needed to determine whether nicotinic cholinergic mechanisms are involved in the affective manifestations of alcohol withdrawal. Those studies, together with the present results, will provide a mechanistic framework for the use of nAChR antagonists for the treatment of alcoholism and the prevention of relapse.

\section{FUNDING AND DISCLOSURE}

The authors declare no conflict of interest.

\section{ACKNOWLEDGMENTS}

This work was supported in part by NIH grants DA017173 and DA024385 to MDB and F31AA018626 to EP.

\section{REFERENCES}

Asher MK, Martin RA, Rohsenow DJ, MacKinnon SV, Traficante R, Monti PM (2003). Perceived barriers to quitting smoking among alcohol dependent patients in treatment. J Subst Abuse Treat 24: 169-174.

Baldwin PR, Alanis R, Salas R (2011). The role of the Habenula in nicotine addiction. J Addict Res Ther S1: 002 (doi:10.4172/21556105.S1-002).

Berrettini WH, Doyle GA (2012). The CHRNA5-A3-B4 gene cluster in nicotine addiction. Molecular psychiatry 17: 856-866.

Burton SM, Tiffany ST (1997). The effect of alcohol consumption on craving to smoke. Addiction 92: 15-26.

CASA (2000). CASA's cost of living adjustment, using the Bureau of Labor Statistics Inflation Calculator, of 1998 data by Harwood, $H$. Report prepared by The Lewin Group for the National Institute on Alcohol Abuse and Alcoholism, 2000. Based on estimates, analyses, and datareported in Harwood, H., Fountain, D., and Livermore, G. (1992). The Economic Costs of Alcohol and Drug Abuse in the United States. Report prepared for the National Institute on Drug Abuse and the National Institute on Alcohol Abuse and Alcoholism National Institutes of Health, U.S. Department of Health and Human Services. NIH Publication No 98-4327. (2005). Rockville, MD.

Ceballos NA (2006). Tobacco use, alcohol dependence, and cognitive performance. J Gen Psychol 133: 375-388.

Chatterjee S, Bartlett SE (2010). Neuronal nicotinic acetylcholine receptors as pharmacotherapeutic targets for the treatment of alcohol use disorders. CNS Neurol Disord Drug Targets 9: 60-76.

Chatterjee S, Steensland P, Simms JA, Holgate J, Coe JW, Hurst RS et al (2011). Partial agonists of the alpha3beta $4^{*}$ neuronal nicotinic acetylcholine receptor reduce ethanol consumption and seeking in rats. Neuropsychopharmacology 36: 603-615.

Chen WJ, Harle LK (2005). Interactive effect of alcohol and nicotine on developing cerebellum: an investigation of the temporal pattern of alcohol and nicotine administration. Alcohol Clin Exp Res 29: 437-442.

Choquet H, Joslyn G, Lee A, Kasberger J, Robertson M, Brush G et al (2013). Examination of rare missense variants in the CHRNA5-A3-B4 gene cluster to level of response to alcohol in the San Diego Sibling Pair study. Alcohol Clin Exp Res 37: 1311-1316.

Collins AC, Burch JB, de Fiebre CM, Marks MJ (1988). Tolerance to and cross tolerance between ethanol and nicotine. Pharmacol Biochem Behav 29: 365-373.

Dani JA, Harris RA (2005). Nicotine addiction and comorbidity with alcohol abuse and mental illness. Nat Neurosci 8: 1465-1470.

Dawson DA (2000). Drinking as a risk factor for sustained smoking. Drug Alcohol Depend 59: 235-249.

Doyon WM, Dong Y, Ostroumov A, Thomas AM, Zhang TA, Dani JA (2013a). Nicotine decreases ethanol-induced dopamine signaling and increases self-administration via stress hormones. Neuron 79: 530-540.

Doyon WM, Thomas AM, Ostroumov A, Dong Y, Dani JA (2013b). Potential substrates for nicotine and alcohol interactions: a focus on the mesocorticolimbic dopamine system. Biochem Pharmacol 86: 1181-1193.

Economidou D, Cippitelli A, Stopponi S, Braconi S, Clementi S, Ubaldi $M$ et al (2011). Activation of brain NOP receptors attenuates acute and protracted alcohol withdrawal symptoms in the rat. Alcohol Clin Exp Res 35: 747-755.

Erwin BL, Slaton RM (2014). Varenicline in the treatment of alcohol use disorders. Ann Pharmacother 48: 1445-1455.

Farook JM, Morrell DJ, Lewis B, Littleton JM, Barron S (2007). Topiramate (Topamax) reduces conditioned abstinence behaviours and handling-induced convulsions (HIC) after chronic administration of alcohol in Swiss-Webster mice. Alcohol Alcohol 42: 296-300. 
Fowler CD, Lu Q, Johnson PM, Marks MJ, Kenny PJ (2011). Habenular alpha5 nicotinic receptor subunit signalling controls nicotine intake. Nature 471: 597-601.

Gallego X, Ruiz-Medina J, Valverde O, Molas S, Robles N, Sabria J et al (2012). Transgenic over expression of nicotinic receptor alpha 5 , alpha 3 , and beta 4 subunit genes reduces ethanol intake in mice. Alcohol 46: 205-215.

Grant BF, Hasin DS, Chou SP, Stinson FS, Dawson DA (2004). Nicotine dependence and psychiatric disorders in the United States: results from the national epidemiologic survey on alcohol and related conditions. Arch Gen Psychiatry 61: 1107-1115.

Gulliver SB, Rohsenow DJ, Colby SM, Dey AN, Abrams DB, Niaura RS et al (1995). Interrelationship of smoking and alcohol dependence, use and urges to use. J Stud Alcohol 56: 202-206.

Hallfors J, Loukola A, Pitkaniemi J, Broms U, Mannisto S, Salomaa V et al (2013). Scrutiny of the CHRNA5-CHRNA3-CHRNB4 smoking behavior locus reveals a novel association with alcohol use in a Finnish population based study. Int J Mol Epidemiol Genet 4: 109-119.

Henningfield JE, Chait LD, Griffiths RR (1984). Effects of ethanol on cigarette smoking by volunteers without histories of alcoholism. Psychopharmacology 82: 1-5.

Hershon HI (1977). Alcohol withdrawal symptoms and drinking behavior. J Stud Alcohol 38: 953-971.

Hillemacher T, Bayerlein K, Wilhelm J, Frieling H, Thurauf N, Ziegenbein $\mathrm{M}$ et al (2006). Nicotine dependence is associated with compulsive alcohol craving. Addiction 101: 892-897.

Hoft NR, Corley RP, McQueen MB, Huizinga D, Menard S, Ehringer MA (2009). SNPs in CHRNA6 and CHRNB3 are associated with alcohol consumption in a nationally representative sample. Genes Brain Behav 8: 631-637.

Holt LJ, Litt MD, Cooney NL (2012). Prospective analysis of early lapse to drinking and smoking among individuals in concurrent alcohol and tobacco treatment. Psychol Addict Behav 26: 561-572.

Hughes JR, Higgins ST, Bickel WK (1994). Nicotine withdrawal versus other drug withdrawal syndromes: similarities and dissimilarities. Addiction 89: 1461-1470.

Hurley LL, Taylor RE, Tizabi Y (2012). Positive and negative effects of alcohol and nicotine and their interactions: a mechanistic review. Neurotox Res 21: 57-69.

Jackson KJ, Sanjakdar SS, Muldoon PP, McIntosh JM, Damaj MI (2013). The alpha3beta ${ }^{*}$ nicotinic acetylcholine receptor subtype mediates nicotine reward and physical nicotine withdrawal signs independently of the alpha5 subunit in the mouse. Neuropharmacology 70: 228-235.

Jacques D, Zdanowicz N, Reynaert C, Janne P, Timary P (2011). Intensity of symptoms from alcohol withdrawal in alcoholdependent patients: comparison between smokers and nonsmokers. Psychiatr Danub 23(Suppl 1): S123-S125.

Joslyn G, Brush G, Robertson M, Smith TL, Kalmijn J, Schuckit M et al (2008). Chromosome 15q25.1 genetic markers associated with level of response to alcohol in humans. Proc Natl Acad Sci USA 105: 20368-20373.

Kalman D, Hayes K, Colby SM, Eaton CA, Rohsenow DJ, Monti PM (2001). Concurrent versus delayed smoking cessation treatment for persons in early alcohol recovery. A pilot study. J Subst Abuse Treat 20: 233-238.

Kamens HM, Andersen J, Picciotto MR (2010). Modulation of ethanol consumption by genetic and pharmacological manipulation of nicotinic acetylcholine receptors in mice. Psychopharmacology 208: 613-626.

Kuzmin A, Jerlhag E, Liljequist S, Engel J (2009). Effects of subunit selective $\mathrm{nACh}$ receptors on operant ethanol self-administration and relapse-like ethanol-drinking behavior. Psychopharmacology 203: 99-108.

Litten RZ, Ryan ML, Fertig JB, Falk DE, Johnson B, Dunn KE et al (2013). A double-blind, placebo-controlled trial assessing the efficacy of varenicline tartrate for alcohol dependence. J Addict Med 7: 277-286.

Majchrowicz E (1975). Induction of physical dependence upon ethanol and the associated behavioral changes in rats. Psychopharmacologia 43: 245-254.

Mihalak KB, Carroll FI, Luetje CW (2006). Varenicline is a partial agonist at alpha4beta2 and a full agonist at alpha7 neuronal nicotinic receptors. Mol Pharmacol 70: 801-805.

Morel C, Fattore L, Pons S, Hay YA, Marti F, Lambolez B et al (2013). Nicotine consumption is regulated by a human polymorphism in dopamine neurons. Mol Psychiatry 19: 930-936.

Muldoon PP, Jackson KJ, Perez E, Harenza JL, Molas S, Rais B et al (2014). The alpha3beta4* nicotinic ACh receptor subtype mediates physical dependence to morphine: mouse and human studies. Br J Pharmacol 171: 3845-3857.

Perez E, De Biasi M (2015). Assessment of affective and somatic signs of ethanol withdrawal in C57BL/6J mice using a short-term ethanol treatment. Alcohol 49 (in press).

Picciotto MR, Zoli M, Rimondini R, Lena C, Marubio LM, Pich EM et al (1998). Acetylcholine receptors containing the beta2 subunit are involved in the reinforcing properties of nicotine. Nature 391: 173-177.

Rahman S, Engleman EA, Bell RL (2014). Nicotinic receptor modulation to treat alcohol and drug dependence. Front Neurosci 8: 426.

Ray LA, Courtney KE, Ghahremani DG, Miotto K, Brody A, London ED (2014). Varenicline, low dose naltrexone, and their combination for heavy-drinking smokers: human laboratory findings. Psychopharmacology 231: 3843-3853.

Rho B, Glick SD (1998). Effects of 18-methoxycoronaridine on acute signs of morphine withdrawal in rats. Neuroreport 9: $1283-1285$

Saitz R (1998). Introduction to alcohol withdrawal. Alcohol Health Res World 22: 5-12.

Salas R, Pieri F, De Biasi M (2004). Decreased signs of nicotine withdrawal in mice null for the beta4 nicotinic acetylcholine receptor subunit. J Neurosci 24: 10035-10039.

Salas R, Sturm R, Boulter J, De Biasi M (2009). Nicotinic receptors in the habenulo-interpeduncular system are necessary for nicotine withdrawal in mice. J Neurosci 29: 3014-3018.

Sparks JA, Pauly JR (1999). Effects of continuous oral nicotine administration on brain nicotinic receptors and responsiveness to nicotine in C57Bl/6 mice. Psychopharmacology 141: 145-153.

Tizabi Y, Bai L, Copeland RL Jr., Taylor RE (2007). Combined effects of systemic alcohol and nicotine on dopamine release in the nucleus accumbens shell. Alcohol Alcohol 42: 413-416.

Wang JC, Grucza R, Cruchaga C, Hinrichs AL, Bertelsen S, Budde JP et al (2009). Genetic variation in the CHRNA5 gene affects mRNA levels and is associated with risk for alcohol dependence. Mol Psychiatry 14: 501-510.

WHO (2011). World Health Organization. Management of Substance Abuse Team. Global Status Report on Alcohol and Health. World Health Organization: Geneva, Switzerland. xii, 286 p.

Zhang L, Dong Y, Doyon WM, Dani JA (2012). Withdrawal from chronic nicotine exposure alters dopamine signaling dynamics in the nucleus accumbens. Biol Psychiatry 71: 184-191.

Zhu KJ, Quan C, Zhang C, Liu Z, Liu H, Li M et al (2014). Combined effect between CHRNB3-CHRNA6 region gene variant (rs6474412) and smoking in psoriasis vulgaris severity. Gene 544: 123-127.

Supplementary Information accompanies the paper on the Neuropsychopharmacology website (http://www.nature.com/npp) 